
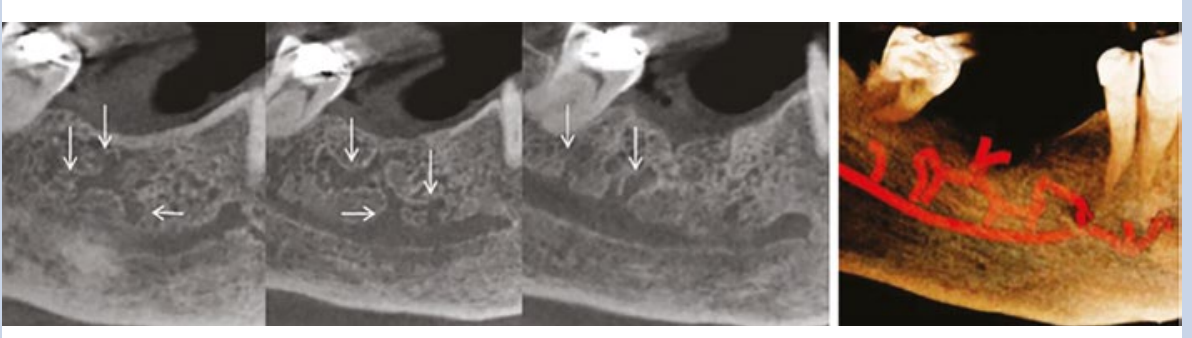

Fig. 6 Localised increase in vascularity in the mandible

Some patients have more pronounced salivary gland depressions: sublingual gland depressions (Fig. 2a) and submandibular gland depressions (Fig. 2b).

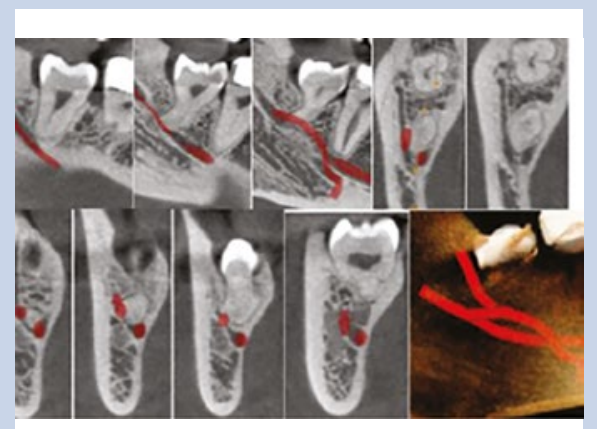

Fig. 7 Bifurcations of the inferior dental canal

Figure 3 shows a Stafne defect on the lingual surface of the mandible - a normal anatomical variant.

CBCT is also beneficial in assessing anatomy outside the dental alveolar region, including the zygoma, paranasal sinuses and airway.

Case two shows a СВCT of a 60 -year-old (Fig. 4a), planning for implant placement in the 16 . A reconstructed panoramic view shows the 16

to be fractured and the right maxillary sinus to have increased density and a low positioned inferior border.

Coronal and sectional views (Fig. 4b) show an increase in the thickness and density of the tissues lining the maxillary sinuses, and a

possible oroantral communication between the apex of the mesial buccal root of the 16 and maxillary sinus.

One of the complications with implant placement can be neurosensory alterations where neurovascular structures have not been accurately identified and protected.

Figure 5 shows a mental foramen which can vary in number, size, shape and location. Figure 6 shows a localised increase in vascularity in the mandible and Figure 7 shows bifurcations of the inferior dental canal.

CBCT is not without its limitations. Existing restorations, treatments and implants can result in a scatter and beam hardening artefact, which can reduce the diagnostic quality of the images. However, adjustments to the scan parameters and patient positioning can minimise this. CBCT is also limited in its ability to accurately represent the internal structure of soft tissues and soft tissue lesions.

Overall, СBCT has revolutionised implant dentistry. Advancements in the technology have pioneered development in scanning equipment and innovations in viewing software allow for more precise treatment planning.

For further information on CT Dent services and cases visit www.ct-dent.co.uk or call 02074875717.

\section{Preserve and protect}

The cleaning and disinfection of your treatment centre will preserve its life as well as protecting both patients and staff against infection. That is why Belmont has developed a range of care products to ensure their new equipment retains its aesthetics.

The products can be divided into two categories: chair maintenance (B100 \& B300) and dental unit waterline protection (B700 \& B900).

Chairs need to be wiped down between patients and for such regular use you need a fast-acting upholstery cleaner that will not damage artificial leather; B300 does just that. It has reduced levels of alcohol so that over time it will prevent brittle, cracked surfaces. However, it is bactericidal (even killing TB), yeasticidal and has limited virucidal impact, being effective against non-enveloped viruses, including norovirus.

The perfect adjunct to this is B100, an intensive cleaner designed for occasional use, to remove stains of all kinds as well as discolouration.

Despite its rigorous cleaning action, it will not damage your upholstery.

The daily care of your waterlines is another routine hygiene task that must be carried out. B700 is a tried and tested maintenance solution for waterlines. It maintains the water flowing through your unit and will minimise the potential for biofilm formation. B700 is supplied in a single-dose sachet. B700 is also non-effervescent, which means it can be used instantly.

Before you start using B700 it is essential that you test and 'shock' your system using the $\mathrm{B} 900 \mathrm{kit}$. This will remove any existing biofilm. Thereafter, you're advised to perform this quarterly to prevent the build-up of future biofilm. The B900 kit contains a box of five shock bottles, tester strips and ten dipstick slides for 'before' and 'after' evaluation.

For your convenience Belmont have also put together a starter kit, called B500, so that you can test and treat your water lines with minimal investment.

Whether you have a new or older Belmont unit, you can contact your dealer to order products from the range and ensure your unit remains looking and functioning optimally.

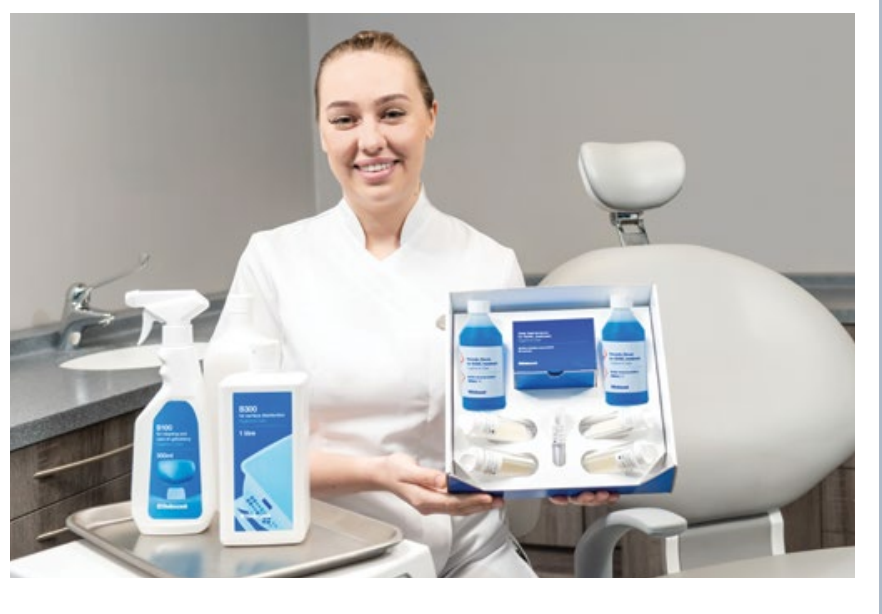

